\title{
Fred T. Mackenzie: Gentleman, Scholar, Mountaineer and Model Colleague
}

\author{
Eric Heinen De Carlo • Rolf S. Arvidson • Lei Chou • Christopher L. Sabine • \\ George W. Luther
}

Received: 19 November 2013/ Accepted: 29 November 2013

(C) Springer Science+Business Media Dordrecht 2013

This special Volume of Aquatic Geochemistry is dedicated to Fred T. Mackenzie (Fig. 1), a world class geologist and (bio) geochemist, particularly in the field of carbonates. Fred is currently Emeritus Professor of Oceanography and Geology and Geophysics in the Department of Oceanography, School of Ocean and Earth Sciences and Technology, at the University of Hawaii at Manoa (http://www.soest.hawaii.edu/oceanography/faculty/ mackenzie.html). Fred began his professional career with a brief stint as a geologist with Shell Oil Company after which he moved to the Bermuda Biological Station for Research (now Bermuda Institute of Ocean Sciences or BIOS), then joined the faculty at Northwestern University in 1967. He was at Northwestern formally through 1982 when he moved to the University of Hawaii, although he remained an adjunct professor with Northwestern and BIOS thereafter, Fred spent the next 32 years at the UH, where the authors of this preface and countless others have enjoyed and benefited from his collegiality, mentorship and, for several of us, a close friendship that developed over the many years interacting with this great scholar. Throughout his years in academe, Fred enjoyed many formal and informal affiliations with other institutions of higher learning including

\footnotetext{
E. H. De Carlo $(\bowtie)$

Department of Oceanography, University of Hawaii at Manoa, Honolulu, HI 96822, USA e-mail: edecarlo@soest.hawaii.edu

R. S. Arvidson MARUM, Fachbereich Geowissenschaften FB5, Universität Bremen, Klagenfurter Straße, 28359 Bremen, Germany

L. Chou

Département des Sciences de la Terre et de l'Environnement, Service de Biogéochimie et Modélisation du Système Terre, Océanographie Chimique et Géochimie des Eaux, Université Libre de Bruxelles, Brussels, Belgium

C. L. Sabine

NOAA/PMEL, 7600 Sand Point Way, Seattle, WA 98115, USA

G. W. Luther

College of Earth Ocean and Environment, University of Delaware, Lewes, DE 19958, USA
} 
the West Indies Laboratory of Fairleigh Dickinson University, Harvard University, John Hopkins University, the Université Libre de Bruxelles, and the Stareso Marine Laboratory (Corsica). In 1997, Fred founded and was the first Program Director of the Bachelor of Science degree program in Global Environmental Science (GES) in the UH Oceanography Department. Fred's publication list is so extensive in numbers and so broad in scope that it does not do justice to simply refer to his nearly 300 journal articles, volume chapters, books and reports to national and international committees, yet it is a formidable task to describe all the areas of research in which he has published. A similar comment can be made regarding the many awards that Fred has received over the years from various institutions, governments, and professional associations (Fig. 2).

Fred has been widely recognized as a visionary and broad minded geochemist who could hone in on the smallest (but always critically important) details of a laboratory experiment while at the same time expounding on the significance of the experiment to our understanding of global scale biogeochemical cycles. Fred's dedication to hard work and attention to detail have been reflected in his career through his associations with some other great thinkers of our time including Robert A. Berner, Robert M. Garrels, John Morse, and Roland Wollast (Fig. 3), to name only a few. Like Fred, all of these preeminent scientists lived and breathed science but were also great humanists and enjoyed life to the fullest. One of us (EDC) will always remember Fred's story of how, when he was in graduate school, his advisor would conduct bed checks in the evening to ensure that students were getting enough sleep and were not distracted by any outside late-night activities. This story generally surfaced during discussions in which we lamented the seeming lack of dedication and work ethics of some of "the younger generation".

The other side of Fred, if one wants to pin his scientific persona to two aspects, is that of a sharing colleague, a thoughtful and considerate listener, and a caring friend as well as mentor to everyone (Fig. 4). Fred's approach to science is one characterized by sharing all research and knowledge freely to help advance science beyond individual contributions to get where we are today. In that regard, those of us who have been fortunate to have benefited from an association with Fred have found it easier to shine because we are standing on the shoulders of this scientific giant. Fred has given much to the community, and it is with great pride and admiration that Aquatic Geochemistry recognizes his yeoman like work for the journal since its inception. His leadership along with that of our first editor-in-chief and his good friend, John W. Morse, were essential to the journal's success.

Beyond science, Fred has always been an avid athlete and adventurer. His athletic endeavors have ranged from boxing to mountaineering, the latter of which he has continued throughout his life. He has conquered many of the world's most formidable peaks on multiple continents and always marvels at the beauty of nature when viewed from above. Many of his students throughout the years have participated in his mountaineering activities, and those of us who have not still hope to do so soon, if we could only keep up!

All the contributors to this special issue are former students, colleagues and friends of Fred's who wish to recognize his contributions to our own careers and life and honor him while he can still read these words (Fig. 5). Alas, too many special issues honor our colleagues after they pass and we did not want this to be the case for Fred! The broad scope and variety of contributions in this volume attest to the breadth of Fred's own scientific interests and reflect how influential he has been in so many aspects of the field of biogeochemistry, from observational to experimental and on to modeling 
Fig. 1 Fred T. Mackenzie at home in Hawaii with the Koolau range in the background
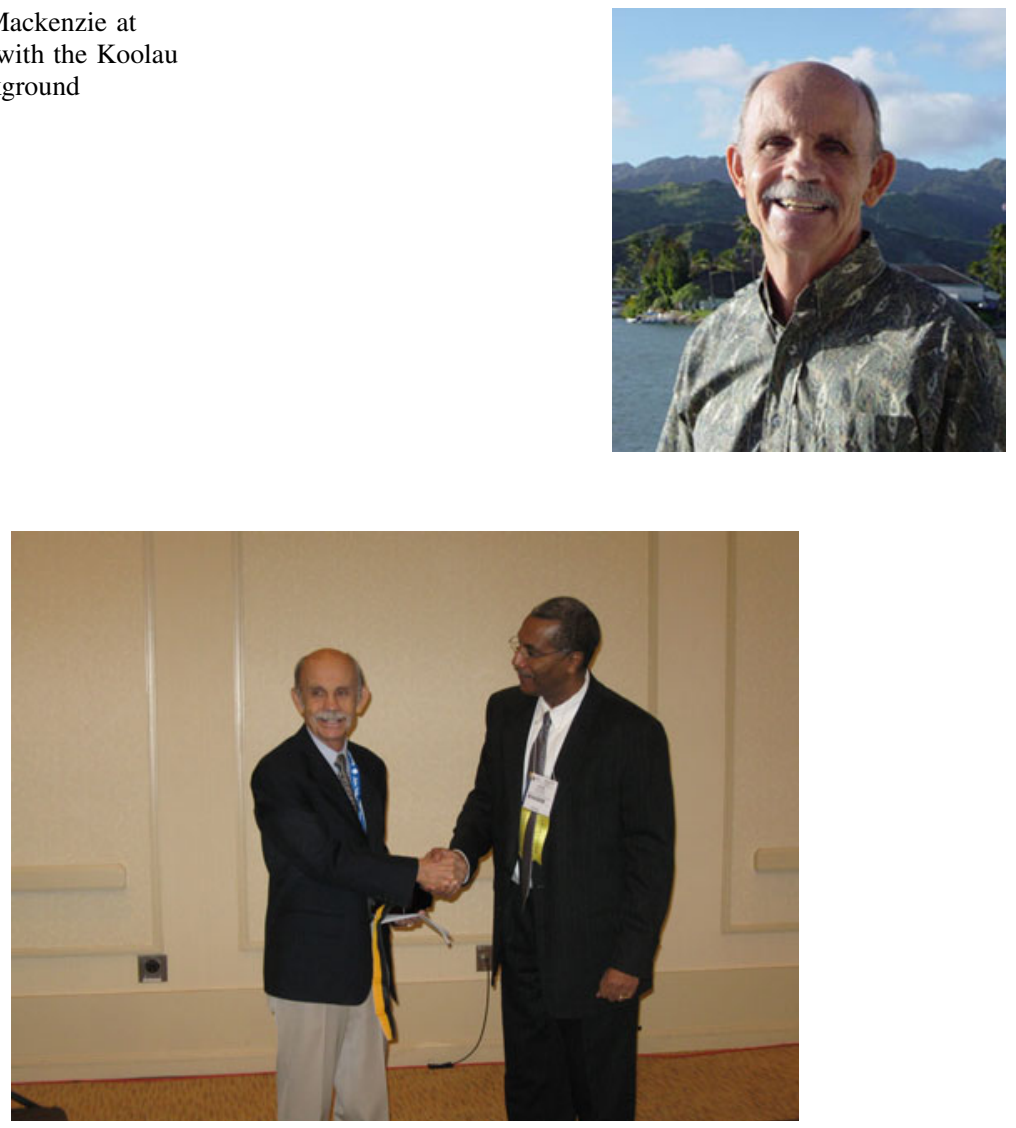

Fig. 2 Fred receiving the Geochemistry medal from ACS, Salt Lake City, UT (3/23/2009)

studies. Andersson et al. (2013) describe how deep seawater conditions in the Pacific and Atlantic Oceans correspond to projected conditions in the surface ocean as a result of anthropogenic $\mathrm{CO}_{2}$ uptake and how preservation of $\mathrm{CaCO}_{3}$ minerals, and the occurrence and distribution of deep-sea marine calcifiers support the hypothesized negative effects of ocean acidification on the production and preservation of $\mathrm{CaCO}_{3}$ in surface seawater. Drupp et al. (2013) describe the variability of carbon system parameters in coral reef environments and how long term high frequency (i.e., real time) observations are critical for reliably characterizing these systems. Similarly De Carlo et al. (2013) present a time series of carbon system parameters in a northwestern Mediterranean embayment and use data from Hawaii to evaluate errors in $\mathrm{CO}_{2}$ flux estimates that may arise from using different temporal frequencies. Lee et al. (2013) use isotopic analysis to constrain the carbon budget of a tropical watershed, while Joo et al. (2013) evaluate human perturbations on the global nitrogen flux through mass and isotopic fluxes. Another paper dealing with mass balances is provided by Carbonnel et al. (2013) who examine the retention of silica in the riverine and estuarine Scheldt tidal system. Khalil et al. (2013) evaluate the spatial and temporal variability in the recycling of organic matter in temperate and eutrophic estuaries, while Briggs et al. 


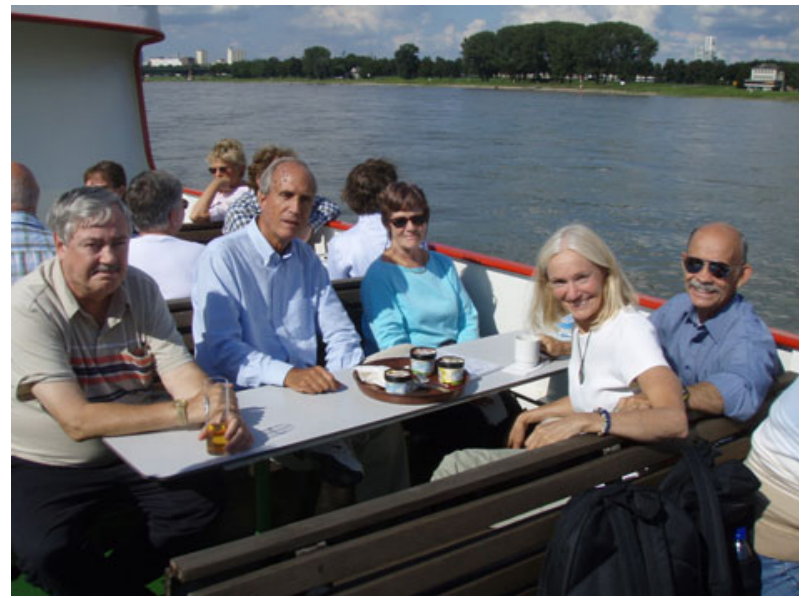

Fig. 3 "Humanists and scientists" enjoying a Rhine River cruise in Koln, Germany, Aug 23, 2007. Left to right The late John Morse, Robert A. and Elizabeth K. Berner, and Judy and Fred T. Mackenzie

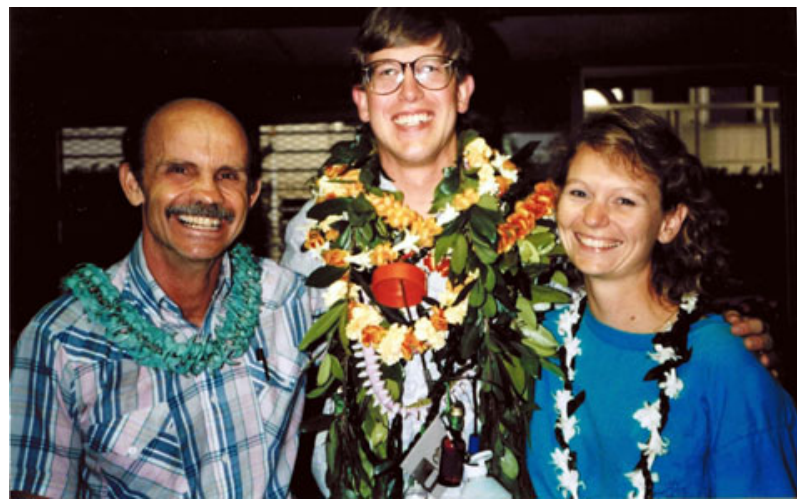

Fig. 4 Fred with Chris and Laura Sabine at Chris' PhD defense in 1992

(2013) describe the use of multiple end member isotopic mixing diagrams to constrain the sources of organic matter to tropical coastal sediments observed during their field studies. Three other papers describe models of elemental cycles in natural systems to round out this special issue following on Fred and his colleagues' long-standing big picture view of the world. These include the use by Berner (2013) of a relatively simple diagram to examine the carbon and phosphorus cycles and how these affect atmospheric $\mathrm{CO}_{2}$ and $\mathrm{O}_{2}$. Another by Tanaka et al. (2013) evaluates ecosystem response in Kaneohe bay through the modeling of nitrogen cycling in this tropical embayment. Finally, Regnier et al. (2013) describe how reaction transport models (RTM) can be combined with high resolution data to elucidate the interplay of complex estuarine processes including net ecosystem metabolism, carbon and nutrient fluxes and how their approach provides integrated assessments of the air-water $\mathrm{CO}_{2}$ fluxes along river-estuary-coastal zone continua. The RTM can be applied to scales ranging from regional to global. 


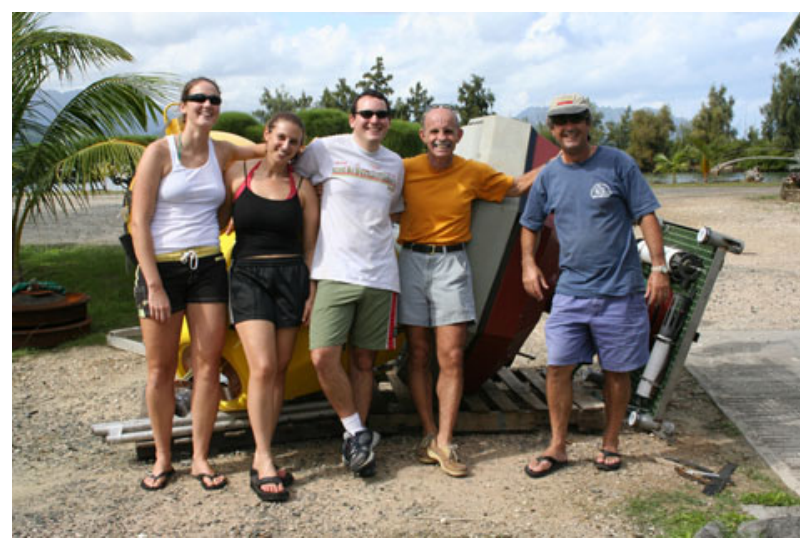

Fig. 5 Left to right Laura deGelleke (UH), Rachel Massaro (UH), Noah Lawrence Slavas (PMEL), Fred T. Mackenzie and Eric Heinen De Carlo immediately prior to the launch of CRIMP-CO ${ }_{2}$, the first PMEL Coastal $\mathrm{MAPCO}_{2}$ buoy, in Kaneohe Bay, Hawaii, November 25, 2005

\section{References}

Andersson AJ, Bates NR, Jeffries MA, Freeman K, Shaun Stringer CD, Betzler E, Mackenzie FT (2013) Clues from current high $\mathrm{CO}_{2}$ environments on the effects of ocean acidification on $\mathrm{CaCO}_{3}$ preservation. Aquat Geochem. 19(5-6):353-369

Berner RA (2013) An earth systems diagram for the global cycles of carbon and phosphorus and their effects on atmospheric $\mathrm{CO}_{2}$ and $\mathrm{O}_{2}$. Aquat Geochem. 19(5-6):565-568

Briggs RA, Ruttenberg KC, Glazer BT, Ricardo AE (2013) Constraining sources of organic matter to tropical coastal sediments: consideration of non-traditional end members. Aquat Geochem. 19(5-6):543-563

Carbonnel V, Vanderborght J-P, Chou L (2013) Silica mass-balance and retention in the riverine and estuarine scheldt tidal system (Belgium/The Netherlands). Aquat Geochem. 19(5-6):501-516

DeCarlo EH, Mousseau L, Passafiume O, Drupp PS, Gattuso J-P (2013) Carbonate chemistry and air-sea $\mathrm{CO}_{2}$ flux in a NW Mediterranean bay over a four-year period: 2007-2011. Aquat Geochem. 19(5-6): 399-442

Drupp PS, De Carlo EH, Mackenzie FT, Sabine CL, Feely RA, Shamberger KE (2013) Comparison of CO dynamics and air-sea gas exchange in differing tropical reef environments. Aquat Geochem. 19(5-6): 371-397

Joo YJ, Li DD, Lerman A (2013) Global nitrogen cycle: pre-anthropocene mass and isotope fluxes and the effects of human perturbations. Aquat Geochem. 19(5-6):477-500

Khalil K, Raimonet M, Laverman AM, Yan C, Andrieux-Loyer F, Viollier E, Deflandre B, Ragueneau O, Rabouille C (2013) Spatial and temporal variability of sediment organic matter recycling in two temperate eutrophicated estuaries. Aquat Geochem. 19(5-6):517-542

Lee KY, Syakir MI, Clark ID, Veizer J (2013) Isotope constraints on the aquatic carbon budget: Langat Watershed, Malaysia. Aquat Geochem. 19(5-6):443-475

Regnier P, Arndt S, Goossens N, Volta C, Laruelle GG, Lauerwald R, Hartmann J (2013) Modeling estuarine biogeochemical dynamics: from the local to the global scale. Aquat Geochem. 19(5-6):591626

Tanaka K, Guidry MW, Gruber N (2013) Ecosystem responses of the subtropical Kaneohe Bay, Hawaii, to climate change: a nitrogen cycle modeling approach. Aquat Geochem. 19(5-6):569-590 